\title{
Spectral Characteristics of Highly Fluorescent 2-(N,N-dimethylamino)tryptanthrin
}

\author{
Jun Kawakami ${ }^{1 *}$, Takuma Kadowaki ${ }^{1}$, Mari Ikeda ${ }^{2}$, Yoichi Habata ${ }^{3}$, Shunji Ito ${ }^{1}$, \\ and Haruo Kitahara ${ }^{4}$ \\ 1 Graduate School of Science and Technology, Hirosaki University, 3 Bunkyo-cho, Hirosaki, Aomori 036-8561, Japan \\ 2 Education Center, Faculty of Engineering, Chiba Institute of Technology, 2-1-1 Shibazono, Narashino, Chiba 275-0023, Japan \\ 3 Department of Chemistry, Faculty of Science, Toho University, 2-2-1 Miyama, Fnabashi, Chiba 274-8510, Japan \\ 4 Kitahara Laboratory Co. Ltd, 3 Bunkyo-cho, Hirosaki, Aomori 036-8561, Japan \\ * Corresponding author: Fax: 81-172-39-3541, and/or e-mail: jun@hirosaki-u.ac.jp
}

We previously reported that 2-aminotryptanthrin $\left(\mathbf{T} 2 \mathbf{N H}_{2}\right)$ possesses excellent photophysical properties such as wide-wavelength absorption and emission in the visible region and a high fluorescence quantum yield. It also exhibits large positive fluorescent solvatochromism. In this study, we synthesized 2-( $N, N$-dimethylamino)tryptanthrin (T2NMe $)$, from which we expected a substantial bathochromic shift of the emission band to the near-infrared (NIR) region by acceleration of intramolecular charge transfer. As such, the emission maxima $\left(\lambda_{f, \max }\right)$ of T2NMe 2 in some solvents were observed in the NIR region.

Key words: Tryptanthrin, Near-infrared fluorescent dye, Solvatochromism, Intramolecular charge transfer

\section{INTRODUCTION}

Tryptanthrin is a weakly basic alkaloid found in a number of plant species [1] that exhibits antimicrobial activity against various pathogenic bacteria and fungi [2]. In particular, it demonstrates a significant antifungal activity against Malassezia furfur, which causes atopic dermatitis [3], and is also effective in the treatment of contact dermatitis (delayed-type allergy) [4]. Therefore, it has a potential use as a therapeutic drug for various conditions as well as applications in cosmetics. In previous studies, we synthesized various tryptanthrin derivatives and investigated their antimicrobial properties against a fungus (M. furfur) and gram-positive bacterium (methicillin-resistant Staphylococcus aureus, MRSA). The antifungal and antibacterial activities of the derivatives were influenced by the tryptanthrin substituents, with the halogen-substituted tryptanthrin derivatives exhibiting the highest potency against $M$. furfur and MRSA [5, 6].

Some tryptanthrin derivatives were found to exhibit fluorescence on being synthesized as antimicrobial agents. We found that 2-aminotryptanthrin ( $\left.\mathbf{T} 2 \mathbf{N H}_{2}\right)$ had especially excellent photophysical properties such as wide-wavelength absorption and emission in the visible region and a high fluorescence quantum yield [7]. The fluorescence spectra of $\mathbf{T} \mathbf{2} \mathbf{N H}_{2}$ in solvents with different polarities demonstrated large positive fluorescent solvatochromism. The emission maxima $\left(\lambda_{\mathrm{f}}, \max \right)$ were red-shifted with increasing polarity in both protic and aprotic solvents, but the shift was more pronounced in the samples dissolved in protic alcohols. The emitted colors changed from green to red with increasing solvent polarity. $\mathbf{T} 2 \mathbf{N H}_{2}$ possesses a planar, polar structure with effective intramolecular charge transfer (ICT) between the carbonyl group of the five-membered ring and the amino group. The large fluorescent solvatochromism is attributable to the influence of the ICT, although stabilization by hydrogen bonding would also contribute in the case of protic solvents [8]. $\mathbf{T} 2 \mathbf{N H}_{2}$ and its derivatives have widespread potential applications in highly diverse fields, such as labeling reagents, chemosensors, laser dyes, photosensitizers, and fluorescent organic devices. With regard to their various applications, it is necessary for these dyes to absorb and emit at longer wavelengths. We expect that they could be of particular interest as organic fluorescent dyes for fluorescent imaging probes in biological research.

The near-infrared (NIR) region $(650-900 \mathrm{~nm})$ is referred to as the "optical window" of cells and tissues due to the lack of efficient endogenous absorbers in this spectral range and the subsequent high penetration depth (of the order of a few millimeters) in most tissues [9]. Organic fluorescent dyes that emit NIR fluorescence are preferable for applications in biological systems as they can reduce auto-fluorescence and photodamage to the living cells. The absorption maxima $\left(\lambda_{\mathrm{a}, \max }\right)$ of $\mathbf{T} \mathbf{2} \mathbf{N H}_{\mathbf{2}}$ are at $447 \mathrm{~nm}$ (in toluene) and $464 \mathrm{~nm}$ (in methanol), and the emission maxima $\left(\lambda_{\mathrm{f}, \max }\right)$ are at $516 \mathrm{~nm}$ (in toluene) and $632 \mathrm{~nm}$ (in methanol). Therefore, we planned to shift the $\lambda_{\mathrm{a} \text {, max }}$ and $\lambda_{\mathrm{f}, \max }$ of $\mathbf{T} 2 \mathbf{N H}_{2}$ to longer wavelengths by accelerating the ICT. As such, we synthesized 2-(N,N-dimethylamino) tryptanthrin (T2NMe2), in which the dimethylamino group are better electron donor than amino group of $\mathbf{T} \mathbf{2} \mathbf{N H}_{2}$. Herein, we report the details of our study on the spectral characteristics of compound $\mathbf{T} \mathbf{2} \mathbf{N M e}_{2}$ in comparison with compound $\mathbf{T} 2 \mathbf{N H}_{2}$.

\section{EXPERIMENTAL}

2.1. General

The ${ }^{1} \mathrm{H}$ and ${ }^{13} \mathrm{C}$ NMR spectra were recorded on a JEOL JNM-ECA 500 spectrometer with tetramethylsilane (TMS) as the internal standard. The UV-visible absorption spectra were acquired on a JASCO-V670 spectrometer. The high-resolution mass spectra (HRMS) were obtained using electrospray ionization (ESI) with a HITACHI NanoFrontier LD spectrometer. The fluorescence spectra were acquired on a Hitachi F-4500 fluorophotometer. 
Measurement of the absorption and fluorescence spectra were conducted in 13 solvents with different relative permittivities $(\varepsilon)$ at room temperature, where the concentrations of all of the sample solutions were 1.0 $\times 10^{-5} \mathrm{~mol} \mathrm{dm}^{-3}$ and no intermolecular interactions were found. The 13 solvents were toluene ( $\mathrm{PhMe}, \varepsilon=2.43$ ), chloroform $\left(\mathrm{CHCl}_{3}, \varepsilon=4.89\right)$, ethyl acetate (EtOAc, $\varepsilon=$ 6.03), tetrahydrofuran (THF, $\varepsilon=7.47$ ), dichloromethane (DCM, $\varepsilon=9.02$ ), dichloroethane (DCE, $\varepsilon=10.74$ ), benzonitrile $(\mathrm{PhCN}, \varepsilon=25.30)$, acetonitrile $(\mathrm{MeCN}, \varepsilon=$ 36.00), $N, N$-dimethylformamide (DMF, $\varepsilon=37.06$ ), dimethylsulfoxide (DMSO, $\varepsilon=47.00$ ), 2-propanol (2-PrOH, $\varepsilon=19.92)$, ethanol (EtOH, $\varepsilon=25.00)$, and methanol $(\mathrm{MeOH}, \varepsilon=32.35)$. The absolute fluorescence quantum yield $\left(\Phi_{\mathrm{f}}\right)$ of $\mathbf{T} 2 \mathbf{N M e} 2$ in DCM was determined to be 0.89 using a HAMAMATSU Quantaurus-QY system. The other $\Phi_{\mathrm{f}}$ values were determined at room temperature relative to that of $\mathbf{T} 2 \mathbf{N M e}_{2}$ in DCM $\left(\Phi_{\mathrm{f}}=0.89\right)$ using solutions of matched absorbance $\left(0.1 \mathrm{~L} \mathrm{~mol}^{-1} \mathrm{~cm}^{-1}\right)$ at the excitation wavelength. In order to gain better understanding of the molecular geometries, molecular orbitals, optical properties, and electronic properties of compounds $\mathbf{T} 2 \mathbf{N H}_{2}$ and $\mathbf{T} 2 \mathbf{N M e}_{2}$, density functional theory (DFT) calculations at the B3LYP/6-31G* level were performed using the SPARTAN ' 10 software package (Wavefunction Inc., Irvine, CA, 2000).

\subsection{Synthesis}

$\mathbf{T}_{2} \mathbf{N M e}_{2}$ was obtained from $\mathbf{T} 2 \mathbf{N H}_{2}$ (synthesized according to Ref. [5]) by Eschweiler-Clarke reaction (Scheme 1) $[10,11]$.

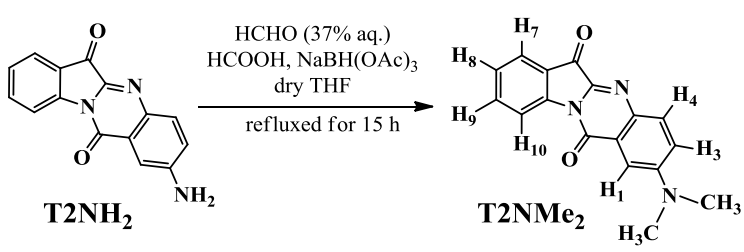

Scheme 1 Synthesis of $2-(N, N$-dimethylamino $)$ tryptanthrin (T2NMe2)

Sodium triacetoxyborohydride $(0.326 \mathrm{~g}, \quad 1.54$ $\mathrm{mmol})$, formic acid $(5 \mathrm{~mL})$, and $37 \%$ aqueous formaldehyde solution (formalin, $10 \mathrm{~mL}$ ) were added to a stirred solution of $\mathbf{T} 2 \mathbf{N H}_{2}(0.0842 \mathrm{~g}$, $0.320 \mathrm{mmol})$ in dry THF $(15 \mathrm{~mL})$. The mixture was refluxed for $15 \mathrm{~h}$ under an argon atmosphere and cooled to room temperature. The reaction mixture was neutralized with saturated aqueous sodium hydrogen carbonate solution, extracted with DCM, washed with distilled water, dried over anhydrous magnesium sulfate, and concentrated under a vacuum to afford the crude product. Column chromatography on alumina with DCM as the eluent yielded pure $\mathbf{T 2 N M e}_{2}$ as a reddish brown solid (0.0929 g, 50.6\%).

T2NMe $2:{ }^{1} \mathrm{H} \quad \mathrm{NMR} \quad \delta_{\mathrm{H}} \quad\left(\mathrm{DMSO}-d_{6}, \quad 500 \mathrm{MHz}\right.$, $\left.\mathrm{Me}_{4} \mathrm{Si}\right): 8.50\left(1 \mathrm{H}, \mathrm{d}, J=8.6 \mathrm{~Hz}, \mathrm{H}_{10}\right), 7.80-7.90(2 \mathrm{H}$, $\mathrm{m}, \mathrm{H}_{7}$ and $\left.\mathrm{H}_{9}\right), 7.77\left(1 \mathrm{H}, \mathrm{d}, J=9.2 \mathrm{~Hz}, \mathrm{H}_{4}\right), 7.46$ $(1 \mathrm{H}, \mathrm{t}, J=7.5 \mathrm{~Hz}, \mathrm{H} 8), 7.39(1 \mathrm{H}, \mathrm{d}, J=3.2 \mathrm{~Hz}$, $\left.\mathrm{H}_{1}\right), 7.34\left(1 \mathrm{H}, \mathrm{dd}, J=9.2 \mathrm{~Hz}, 3.2 \mathrm{~Hz}, \mathrm{H}_{3}\right), 3.13$ $\left(6 \mathrm{H}, \mathrm{s}, \mathrm{CH}_{3}\right),{ }^{13} \mathrm{C} \quad \mathrm{NMR} \delta_{\mathrm{C}}\left(\mathrm{CDCl}_{3}, 125 \mathrm{MHz}\right.$, $\left.\mathrm{Me}_{4} \mathrm{Si}\right): \quad 182.26(\mathrm{C}=\mathrm{O}), 158.34(\mathrm{C}=\mathrm{O}), 151.34$, $145.81,140.53,137.44,136.62,132.31,126.78$, $125.04,124.94,122.91,119.03,117.86,107.18$, $40.42\left(\mathrm{CH}_{3}\right)$. HRMS (ESIMS, m/z) calcd: $[\mathrm{M}+\mathrm{H}]^{+}$ 292.1086, $[\mathrm{M}+\mathrm{Na}]^{+}$314.0905; found: $[\mathrm{M}+\mathrm{H}]^{+}$ 292.1174, $\left[\mathrm{M}+\mathrm{Na}^{+}\right.$314.1002. FT-IR [wavenumbers $\left(\mathrm{cm}^{-1}\right)$ ]: $v_{\mathrm{C}=\mathrm{O}}: 1670 ; v_{\mathrm{C}=\mathrm{O}}: 1640$.

\section{RESULTS AND DISCUSSION}

3.1 Spectral characteristics of $\mathbf{T} 2 \mathbf{N H}_{2}$ and $\mathbf{T} 2 \mathbf{N M e}_{2}$

We investigated the solvent effects of $\mathbf{T} \mathbf{2} \mathbf{N H}_{2}$ and T2NMe $_{2}$ in the 13 solvents with different $\varepsilon$. The absorption and fluorescence spectra of T2NMe 2 and the photophysical properties of $\mathbf{T} \mathbf{2} \mathbf{N H}_{2}$ and $\mathbf{T} 2 \mathbf{N M e}_{2}$ are shown in Figure 1 and Table 1 , respectively. The absorption and fluorescence spectra of $\mathbf{T} \mathbf{2} \mathbf{N H}_{2}$ are shown in Figures 2, 3, and 4 of Ref. [8].

(a)

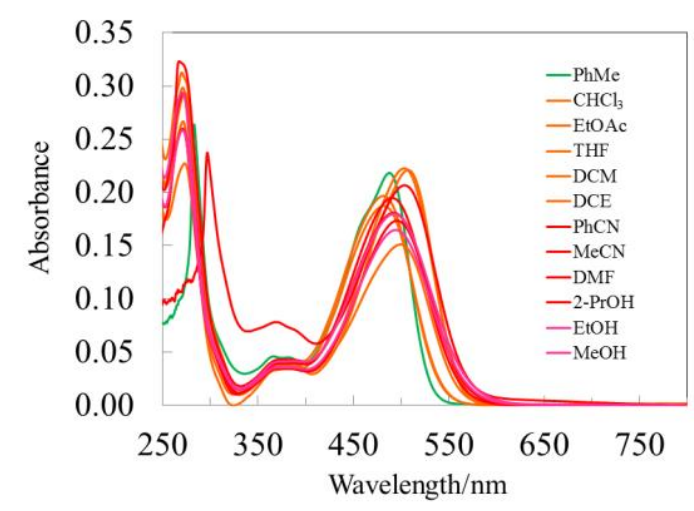

(b)

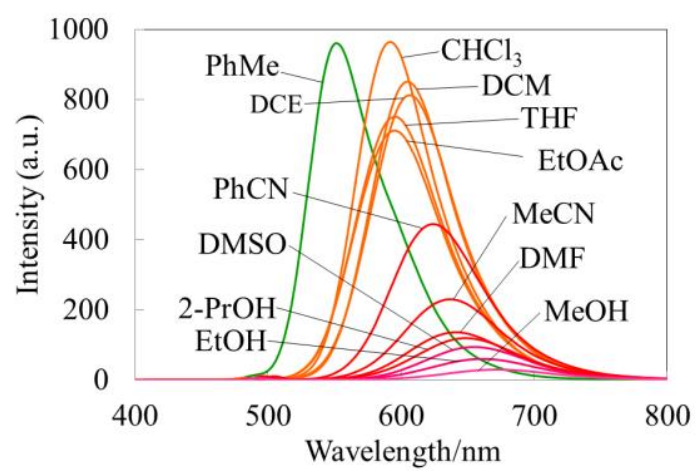

Figure 1. (a) UV-vis absorption and (b) florescence spectra of T2NMe 2 in solvents with different polarities.

In comparison with $\mathbf{T} 2 \mathbf{N H}_{2}, \mathbf{T} 2 \mathbf{N M e}_{2}$, in which a dimethylamino group was installed instead of an amino group, exhibited red-shifted $\lambda_{\mathrm{a}, \max }$ and $\lambda_{\mathrm{f}, \max }$ values. The longest $\lambda_{\mathrm{a}, \max }$ and $\lambda_{\mathrm{f}, \max }$ of $\mathbf{T} 2 \mathbf{N M e}_{2}$ were $508 \mathrm{~nm}$ in $\mathrm{CHCl}_{3}$ and $674 \mathrm{~nm}$ in $\mathrm{MeOH}$, respectively. The $\lambda_{\mathrm{f}, \max }$ of $\mathbf{T 2 N H}_{2}$ are not in the NIR region, but those of T2NMe are in the NIR region for one polar aprotic solvent (DMSO) and three protic solvents (2-PrOH, EtOH and $\mathrm{MeOH})$. T2NMe 2 shows $\Phi_{\mathrm{f}}$ values higher than those of $\mathbf{T 2 N H}_{2}$ and between 0.51 and 0.96 in the seven different aprotic solvents $\left(\mathrm{PhMe} \mathrm{CHCl}_{3}\right.$, EtOAc, THF, DCM, DCE 
Table 1. Absorption maxima $\left(\lambda_{\mathrm{a}, \max }\right)$, molar absorption coefficients $\left(\varepsilon_{\mathrm{a}, \max }\right)$, emission maxima $\left(\lambda_{\mathrm{f}, \max }\right)$, fluorescence quantum yields $\left(\Phi_{\mathrm{f}}\right)$, and Stokes shifts of $\mathbf{T} 2 \mathbf{N H}_{2}$ and $\mathbf{T} 2 \mathrm{NMe}$.

\begin{tabular}{|c|c|c|c|c|c|c|c|c|c|c|}
\hline \multirow{2}{*}{ Solvents } & \multicolumn{2}{|c|}{$\lambda_{\mathrm{a}, \max } / \mathrm{nm}$} & \multicolumn{2}{|c|}{$\log \left(\varepsilon_{\mathrm{a}, \max } / \mathrm{dm}^{-3} \mathrm{~mol}^{-1} \mathrm{~cm}^{-1}\right)$} & \multicolumn{2}{|c|}{$\lambda_{\mathrm{f}, \max } / \mathrm{nm}$} & \multicolumn{2}{|c|}{$\Phi_{\mathrm{f}}$} & \multicolumn{2}{|c|}{ Stokes shifts $/ \mathrm{cm}^{-1}$} \\
\hline & T2NH2 & T2NMe2 & T2NH2 & T2NMe2 & $\mathrm{T}_{2} \mathrm{NH}_{2}$ & T2NMe2 & T2NH2 & T2NMe2 & T2NH2 & T2NMe2 \\
\hline $\mathrm{PhMe}$ & 447 & 488 & 3.97 & 4.34 & 516 & 551 & 0.18 & 0.90 & 2992 & 2343 \\
\hline $\mathrm{CHCl}_{3}$ & 450 & 508 & 4.03 & 4.34 & 560 & 592 & 0.60 & 0.96 & 4365 & 2793 \\
\hline EtOAc & 452 & 481 & 4.12 & 4.29 & 553 & 596 & 0.67 & 0.79 & 4041 & 4011 \\
\hline THF & 457 & 481 & 4.08 & 4.27 & 558 & 595 & 0.59 & 0.82 & 3961 & 3983 \\
\hline DCM & 447 & 503 & 4.07 & 4.35 & 545 & 604 & 0.64 & 0.89 & 4023 & 3324 \\
\hline DCE & 447 & 499 & 4.05 & 4.18 & 547 & 608 & 0.64 & 0.88 & 4090 & 3593 \\
\hline $\mathrm{PhCN}$ & 462 & 504 & 4.16 & 4.32 & 581 & 624 & 0.51 & 0.51 & 4433 & 3816 \\
\hline $\mathrm{MeCN}$ & 451 & 490 & 4.13 & 4.29 & 588 & 637 & 0.56 & 0.28 & 5166 & 4710 \\
\hline $\mathrm{DMF}$ & 472 & 492 & 4.02 & 4.26 & 602 & 641 & 0.31 & 0.17 & 4575 & 4725 \\
\hline DMSO & 477 & 496 & 4.06 & 4.21 & 615 & 654 & 0.30 & 0.12 & 4704 & 4871 \\
\hline 2-PrOH & 481 & 496 & 4.21 & 4.24 & 616 & 650 & 0.28 & 0.15 & 4556 & 4777 \\
\hline EtOH & 475 & 497 & 4.24 & 4.22 & 624 & 660 & 0.17 & 0.08 & 5027 & 4969 \\
\hline $\mathrm{MeOH}$ & 464 & 493 & 4.19 & 4.25 & 632 & 674 & 0.12 & 0.04 & 5729 & 5447 \\
\hline
\end{tabular}

and $\mathrm{PhCN}$ ). The $\Phi_{\mathrm{f}}$ values of $\mathbf{T} \mathbf{2} \mathbf{N M e}_{2}$ are lower than those of $\mathbf{T} 2 \mathbf{N H}_{2}$ in the three polar aprotic solvents $(\mathrm{MeCN}$, $\mathrm{DMF}$, and DMSO) and three protic solvents (2-PrOH, $\mathrm{EtOH}$, and $\mathrm{MeOH}$ ). The $\lambda_{\mathrm{f}, \max }$ of $\mathbf{T} 2 \mathbf{N M e}_{2}$ are at more than $637 \mathrm{~nm}$ in these solvents. Small $\Phi_{\mathrm{f}}$ values of T2NMe in comparison with $\mathbf{T} \mathbf{2} \mathbf{N H}_{2}$ could be due to the smallness of the HOMO-LUMO energy gaps. The molar absorption coefficients $\left(\varepsilon_{\mathrm{a}, \max }\right)$ of $\mathbf{T} 2 \mathbf{N M e}_{2}$ are larger than those of $\mathbf{T 2} \mathbf{N H}_{2}$, with exception of that of EtOH. Brightness is given by the product of $\varepsilon_{\mathrm{a}, \max }$ and $\Phi_{\mathrm{f}}$. Therefore, T2NMe can shine more brightly than $\mathbf{T} \mathbf{2} \mathbf{N H}_{\mathbf{2}}$ in many solvents. Photographs taken of $\mathbf{T} 2 \mathbf{N H}_{2}$ and T2NMe 2 under $365 \mathrm{~nm}$ UV light in different solvents are shown in Figure 2.

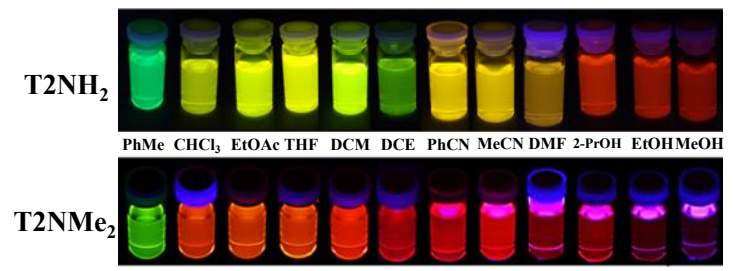

Figure 2. Photographs of $\mathbf{T} 2 \mathbf{N H}_{2}$ and $\mathbf{T} 2 \mathbf{N M e}_{2}$ taken under $365 \mathrm{~nm}$ UV light in different solvents.

The fluorescence of $\mathbf{T} \mathbf{2} \mathbf{N H}_{\mathbf{2}}$ in solvents with different polarities demonstrated large positive fluorescent solvatochromism. The emission maxima were red-shifted with increasing polarity in both protic and aprotic solvents, but the shift was more pronounced in the samples dissolved in the protic alcohols. The emitted colors changed from green $(516 \mathrm{~nm})$ to red $(632 \mathrm{~nm})$ with increasing solvent polarity. In the longer wavelength region, a similar phenomenon was also observed in T2NMe 2 . The emitted colors of T2NMe changed from orange $(592 \mathrm{~nm})$ to red $(674 \mathrm{~nm})$ with increasing solvent polarity, with the exception of green $(551 \mathrm{~nm})$ in $\mathrm{PhMe}$ having the lowest solvent polarity. T2NMer showed a large bathochromic shift of the emission band to the NIR region. The $\lambda_{\text {f, max }}$ values of $\mathbf{T 2 N M e} 2$ in some solvents were in the NIR region. $\mathbf{T}_{2} \mathbf{N H}_{2}$ and $\mathbf{T} 2 \mathbf{N M e}_{2}$ possess planar, polar structures with effective ICT between the carbonyl group of the five-membered ring and the amino group. The large fluorescent solvatochromism of $\mathbf{T} 2 \mathbf{N H}_{2}$ and $\mathbf{T}_{2} \mathrm{NMe}_{2}$ may be attributed to the influence of ICT, although stabilization by hydrogen bonding would be also contribute in the case of protic solvents.

3.2 Strong ICT characteristics of $\mathbf{T} \mathbf{2} \mathbf{N H}_{2}$ and $\mathbf{T} \mathbf{2} \mathbf{N} \mathbf{M e}_{2}$ in their excited states

The molecular structures of $\mathbf{T} \mathbf{2} \mathbf{N H}_{2}$ and $\mathbf{T} \mathbf{2} \mathbf{N M e}_{2}$ were calculated using DFT calculations. The molecular orbital surfaces of the corresponding HOMO and LUMO surfaces of $\mathbf{T} 2 \mathbf{N H}_{2}$ and $\mathbf{T} 2 \mathrm{NMe}_{2}$ and their dipole moments in the ground state $\left(\mu_{\mathrm{G}}\right)$ are shown in Figure 3.

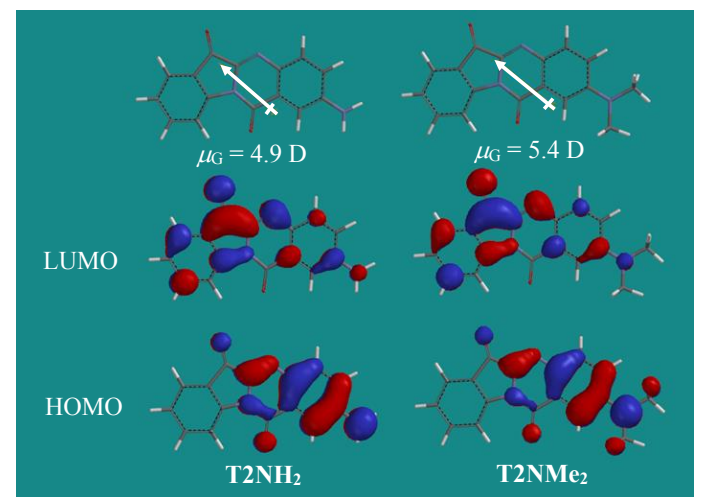

Figure 3. HOMO and LUMO surfaces and $\mu_{\mathrm{G}}$ values of $\mathbf{T}_{2} \mathbf{N H}_{2}$ and $\mathbf{T}_{2} \mathrm{NMe}_{2}$ according to DFT calculations.

In $\mathbf{T}_{2} \mathbf{N H}_{2}$ and $\mathbf{T} 2 \mathbf{N M e}_{2}$, the electrons are localized in the amino group in the HOMO and in the carbonyl group of the five-membered ring in the LUMO. Electronic transitions are $\pi-\pi^{*}$, originating from the amino or dimethylamino groups. These results show that $\mathbf{T} 2 \mathbf{N H}_{2}$ and $\mathbf{T} 2 \mathbf{N M e}_{2}$ have ICT characteristics. The $\mu_{\mathrm{G}}$ values of $\mathbf{T}_{2} \mathbf{N H}_{2}$ and T2NMe2 were 4.9 Debye (D) and $5.4 \mathrm{D}$, respectively. The solvatochromic shift in the ground state is smaller than that in the excited state for both $\mathbf{T} 2 \mathbf{N H}_{2}$ and T2NMe2, as shown in Table 1. These results indicate that the dipole moments of the excited state $\left(\mu_{\mathrm{E}}\right)$ are larger than those in $\mu_{\mathrm{G}}$. Solvent-induced spectral shifts are often interpreted in terms of the Lippert-Mataga equation (1) $[12,13,14]$ : 
$\Delta v=2\left(\mu_{\mathrm{E}}-\mu_{\mathrm{G}}\right)^{2} \Delta f / \mathrm{hca}^{3}+$ constant

$\Delta f=\{(\varepsilon-1) /(2 \varepsilon+1)\}-\left\{\left(\mathrm{n}^{2}-1\right) /\left(2 \mathrm{n}^{2}+1\right)\right\}$

where h $(6.6256 \times 10-27 \mathrm{erg} \mathrm{s})$ is Planck's constant, c $\left(2.9979 \times 1010 \mathrm{~cm} \mathrm{~s}^{-1}\right)$ is the speed of light, $a$ is the radius of the cavity in which the fluorophore resides, $V_{\mathrm{A}}$ and $\nu_{\mathrm{F}}$ are the wavenumbers $\left(\mathrm{cm}^{-1}\right)$ of the absorption and emission bands, respectively. Equation (1) describes the Stokes shifts $\left(\Delta v=v_{\mathrm{A}}-v_{\mathrm{F}}\right)$ in terms of the change in dipole moment of the fluorophore $\left(\Delta \mu=\mu_{\mathrm{E}}-\mu_{\mathrm{G}}\right)$ and the dependence of the dipole energy on the $\varepsilon$ values and refractive index (n) of the solvent. It also accounts for the general solvent effect, but it does not account for specific solvent-fluorophore interactions, such as those involved in hydrogen bonding [15]. The Lippert-Mataga plots for $\mathbf{T}_{2} \mathbf{N H}_{2}$ and $\mathbf{T}_{2} \mathrm{NMe}_{2}$ in aprotic solvents are shown in Figure 4.

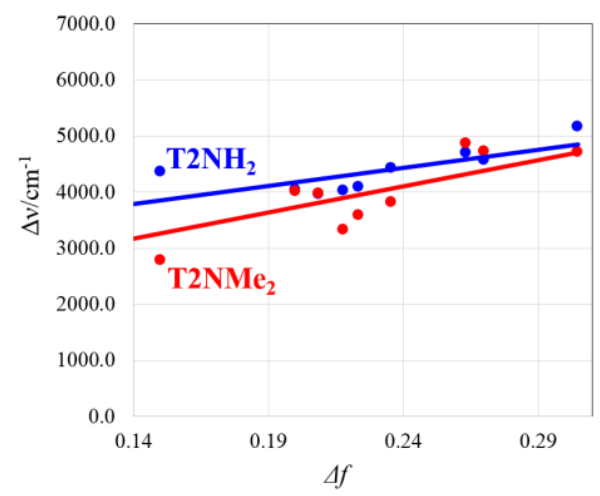

Figure 4. Lippert-Mataga plots of $\mathbf{T} 2 \mathbf{N H}_{2}$ and $\mathbf{T} 2 \mathbf{N M e}_{2}$ showing $\Delta v$ versus $\Delta f$.

From the slopes in this plot, the change in the dipole moment $(\Delta \mu)$ of the fluorophore upon electronic excitation $\left(\mu_{\mathrm{E}}-\mu_{\mathrm{G}}\right)$ was estimated, assuming the molecular radius as the cavity radius [15]. The molecules under consideration are non-spherical; hence, the substitution of the molecular radius for the cavity radius is only approximate. The molecular radii for $\mathbf{T} 2 \mathbf{N H}_{2}(6.03 \AA)$ and $\mathbf{T} 2 \mathbf{N M e}_{2}(6.66 \AA)$ were obtained from DFT calculations. The $\Delta \mu$ values for $\mathbf{T}_{2} \mathbf{N H}_{2}$ and $\mathbf{T}_{2} \mathrm{NMe}_{2}$ were estimated to be $11.9 \mathrm{D}$ and 16.5 D, respectively (Table 2).

Table 2. Molecular radii ${ }^{\mathrm{a})}$ and $\mu_{\mathrm{G}}$ and $\mu \mathrm{E}$ values of $\mathbf{T} 2 \mathbf{N H}_{2}$ and T2NMe.

\begin{tabular}{ccc}
\hline & $\mathbf{1}$ & $\mathbf{2}$ \\
\hline $\mathrm{a} / \AA^{\mathrm{a})}$ & 6.03 & 6.66 \\
$\Delta \mu\left(=\mu_{\mathrm{E}}-\mu_{\mathrm{G}}\right) / \mathrm{D}$ & 11.9 & 16.5 \\
$\mu_{\mathrm{G}} / \mathrm{D}^{\mathrm{a})}$ & 4.9 & 5.4 \\
$\mu_{\mathrm{E}} / \mathrm{D}$ & 16.8 & 21.9 \\
\hline
\end{tabular}

a) Obtained from DFT calculations.

The $\mu \mathrm{E}$ values can be estimated from the $\Delta \mu$ and $\mu_{\mathrm{G}}$ values obtained by the DFT calculations. The $\mu_{\mathrm{E}}$ values of $\mathbf{T}_{2} \mathbf{N H}_{2}$ and $\mathbf{T}_{2} \mathrm{NMe}_{2}$ are $16.8 \mathrm{D}$ and $21.9 \mathrm{D}$, respectively. The $\mu_{\mathrm{E}}$ values would be qualitatively correct and these results can well explain the experimental results. $\mathbf{T} 2 \mathbf{N H}_{2}$ and $\mathbf{T 2 N M e}_{2}$, which have planar structures suitable for effective ICT, are strongly polarized in their excited states. The large fluorescent solvatochromisms of $\mathbf{T} \mathbf{2} \mathbf{N H}_{2}$ and
$\mathrm{T}^{2} \mathrm{NMe}_{2}$ are attributed to the influence of strong ICT in their excited states. In particular, $\mathbf{T} 2 \mathbf{N M e}_{2}$ is very strongly polarized in its excited state. Therefore, fluorescence of T2NMe2, with the strong electron-donating dimethylamino group, was observed in the longer-wavelength NIR region due to the acceleration of the ICT.

\section{CONCLUSION}

We compared the photophysical properties of T2NMe with those of $\mathbf{T} \mathbf{2} \mathbf{N H}_{2}$. Our results showed that $\mathbf{T} \mathbf{2} \mathbf{N M e}_{2}$ exhibited high $\Phi_{\mathrm{f}}$ values and large $\varepsilon_{\mathrm{a}}$, max values in many of the solvents. It also exhibited a large positive fluorescent solvatochromism, as did $\mathbf{T} \mathbf{2} \mathbf{N H}_{2}$. It is also more strongly polarized in the excited state than $\mathbf{T} \mathbf{2} \mathbf{N H}_{2}$ is. Therefore, fluorescence of $\mathbf{T 2 N M e}_{2}$, with the strong electron -donating dimethylamino group, was observed in the longer-wavelength NIR region due to the acceleration of the ICT. Thus, we can conclude that T2NMe can be used as a fluorescent dye in the NIR region, which is referred to as the "optical window" of cells and tissues. As such, we expect that it can potentially be used as an organic fluorescent dye for fluorescent imaging probes in biological research.

\section{ACKNOWLEDGEMENTS}

This work was supported by JSPS KAKENHI Grant Number 25410137.

\section{REFERENCES}

[1] A. Witt and J. Bergman, Curr. Org. Chem., 7, 659-677 (2003).

[2] L. A. Mitscher, W. C. Wong, T. De Meulenere, J. Sulko, and S. Drake, Heterocycles, 15, 1017-1021 (1981).

[3] H. Kitahara, K. Hanada, T. Fukui, Antimicrobial active agents from the Japanese indigo plant and the various compositions of them, Patent No. 5239002, Japan, (Apr. 12, 2013)

[4] H. Kitahara, Y. Sato, D. Ishikawa, K. Kumazawa, A. Nakane, and K. Hanada, Type IV allergic reaction inhibitor, Patent No. 5023317, Japan, (Jun. 29, 2012).

[5] J. Kawakami, N. Matsushima, Y. Ogawa, H. Kakinami, A. Nakane, H. Kitahara, M. Nagaki, and S. Ito, Trans. Mater. Res. Soc. Japan, 36, 603-606 (2011).

[6] J. Kawakami, H. Kakinami, N. Matsushima, A. Nakane, H. Kitahara, M. Nagaki, and S. Ito, J. Comput. Chem. Jpn., 12, 109-112 (2013).

[7] J. Kawakami, Tryptanthrin Derivatives, Patent No. 5448046, Japan, (Jan. 10, 2014).

[8] J. Kawakami, H. Kawaguchi, K. Kikuchi, A. Yamaya, S. Ito, and H. Kitahara, Trans. Mater. Res. Soc. Japan, 38, 123-125 (2013).

[9] K. König, J. Microscopy, 200, 83-104 (2000).

[10] W. Eschweiler, Ber. Dtsch. Chem. Ges., 38, 880-882 (1905).

[11] H. T. Clarke, H. B. Gillespie, and S. Z. Weisshaus, J. Am. Chem. Soc., 55, 4571-4587 (1933).

[12] "Principles of fluorescence spectroscopy" 2nd Ed. by J. R. Lakowicz, Kulwer Academic, New York (1999) pp. 187-194.

[13] E. V. Z. Lippert, Electrochem., 61, 962-975 (1957).

[14] N. Mataga, Y. Kaifu, and M. Koizumi, Bull. Chem. Soc. Jpn., 29, 465-470 (1956).

[15] R. Nandy and S. Sankararaman, Beilstein J. Org. Chem., 6, 992-1001 (2010). 